\title{
Kobe disaster divides earthquake researchers
}

Tokyo. A vigorous debate about the future of Japan's earthquake research - and in particular the earthquake prediction programme, in which Japan has invested substantial amounts of money and manpower over the past 30 years - has been generated by last month's Kobe disaster.

The Prime Minister, Tomiichi Murayama, opening the Diet (parliament) on 20 January, hinted that the prediction programme will be made "more comprehensive" and "nationwide". But earthquake researchers outside the programme say that the experience of the Kobe earthquake indicates that more money and effort should be put into other areas, such as the observation of strong ground motion and basic seismological research.

Citizens and government officials in Kobe say they had no idea that an earthquake of the magnitude of that on 17 January could hit their city. Some researchers claim that this was because too much attention has been focused on the Kanto and Tokai regions near Tokyo, lulling other regions of Japan into a sense of false security.

The Japanese government has designated 10 regions for extensive monitoring of earthquakes. One covers the cities of Kobe, Osaka, Kyoto and Nagoya, and the tip of Awaji Island, where last month's disastrous earthquake was centred.

But the southern Kanto region around Tokyo, as well as the adjoining Tokai region encompassing the Izu Peninsula south of the city, have been subject to even more intensified observations, as this is widely believed to be an area where major earthquakes are likely to occur in the near future.

Kiyoo Mogi, chairman of the Coordination Committee for Earthquake Prediction, and other leaders of the earthquake prediction programme, have repeatedly claimed in public that it may be possible to predict the next major earthquake in the Tokai region. Indeed, the government passed the Largescale Earthquake Countermeasure Act in 1978 on the premise that the Tokai earthquake can be predicted and that, if precursors are detected, the Prime Minister will issue a public warning on the recommendation of Mogi's committee.

Such moves have focused the attention of both the media and the central and local governments on the Kanto-Tokai region over the past two decades. But Harumi Aoki, head of the Coordination Committee for Earthquake Prediction Research in Universities, denies that the result has been to mislead the public.

"We have repeatedly warned that the area [around Kobe] is riddled with active faults," he says. "But in practice only a few earthquakes have been felt, and the danger was therefore not appreciated." He and Mogi point out that a great deal of research has been carried out in the Kobe area. For example, Japan's only 'test field' for earthquake prediction is on the Yamazaki fault, adjacent to that which ruptured during last month's earthquake.

Japan's emphasis on such prediction research is "lopsided" say earthquake engineers who would like to see more research on strong ground motion, where data can provide an instant measure of the scale of a

\section{IMAGE UNAVAILABLE FOR COPYRIGHT REASONS}

\section{Data on strong ground motions might help explain this structural failure.}

disaster in different locations; they also provide important information on the movement of faults, and are needed to improve earthquake-proof designs for buildings and other man-made structures.

Japan has more than 2,000 seismographs for observing strong ground motion operated by national research organizations, universities and private companies. But according to Kenzo Toki, a civil engineer at Kyoto University, most are more than 20 years old and use wax paper and a stylus. Only a few transmit data electronically and most lack a common time axis. This contrasts with the networks for earthquake prediction and tsunami warnings, which are monitored continuously by the headquarters of the Japan Meteorological Agency.

Data from the strong-motion seismographs are collected by the National Research Institute for Earth Science and Disaster Prevention (NIED) in Tsukuba science city northeast of Tokyo. But NIED receives only about $¥ 20$ million a year for this research, compared with about $¥ 4,000$ million a year for earthquake prediction research.

Rapid release of data is essential for assessment of damage immediately after earthquakes. But NIED will not be releasing its first "prompt" report on strong ground motion of the Kobe earthquake for about a month.

Aoki opposes diverting money for prediction research to observations of strong ground motion, pointing out that the budget for disaster prevention is much larger than that for earthquake prediction. "Why not discuss how to use the disaster prevention budget?" he asks. His view is echoed by Mogi, who says that the budget for earthquake prediction research over the past decade "would not even pay for $1 \mathrm{~km}$ of road" around Tokyo.

But funds for university research on disaster prevention are limited. In 1994, only 0.1 per cent of the $¥ 3,342$ billion spent by the government on natural disasters was allocated for research in universities. The Ministry of Education, Science and Culture has no category of research grants suitable for establishing strong-motion observation networks, says Toki, forcing him to turn to the private sector for help when setting up a telemetered network of 10 seismographs in the Kobe-Osaka area last year.

In the United States, seismologists and earthquake engineers frequently work closely together. For example, over the past 5 years they have collected both microquake and strong-motion data from seismograph networks such as the California Institute of Technology's TERRAscope and the Caltech-USGS Broadcast of Earthquakes (CUBE). In Japan, earthquake engineers and seismologists are still "on opposite banks of the river", says Toki, claiming that most seismologists have no interest in strong ground motions that cannot be used for prediction research.

Others complain that the emphasis on prediction research has led to the neglect of basic seismological research. Robert Geller, for example, a geophysicist at Tokyo University, has been campaigning for the replacement of the prediction programme with a new programme that would include more fundamental research aimed at understanding the structure of the Earth (see Nature 352, 275; 1991).

Aoki points out that the prediction programme has led to many fundamental advances in the understanding of the Earth, such as the discovery of the double seismic zone in the subduction zone off the Pacific coast of Japan. Geller says he accepts this example but points out that it was not the aim of the research.

But Aoki and Mogi are both adamant that research on earthquake prediction should be expanded. Given the new concern for inland earthquakes, "observations will be strengthened, never weakened" says Aoki. Mogi adds that "even if other countries give up earthquake prediction, Japan should continue; there is no other country that can deal with this thoroughly".

What changes the government will make, if any, remains unclear. At present, its main advisers are those involved in earthquake prediction research. Unless it consults more widely, a radical redirection of Japan's earthquake research seems unlikely.

David Swinbanks 